\title{
Human-Machine Interaction and Human Resource Management Perspective for Collaborative Robotics Implementation and Adoption
}

\author{
Krystel Libert \\ Business School \\ University of Sherbrooke \\ krystel.libert-morneau@usherbrooke.ca
}

\author{
Nathalie Cadieux \\ Business School \\ University of Sherbrooke \\ nathalie.cadieux@usherbrooke.ca
}

\author{
Elaine Mosconi \\ Business School \\ University of Sherbrooke \\ elaine.mosconi@usherbrooke.ca
}

\begin{abstract}
The shift towards human-robot collaboration (HRC) has the potential to increase productivity and sustainability, while reducing costs for the manufacturing industries. Indeed, it holds great potential for workplaces, allowing individuals to forsake repetitive or physically demanding jobs to focus on safer and more fulfilling ones. Still, integration of humans and machines in organizations presents great challenges to IS scholars due to the complexity of aligning digitalization and human resources. A knowledge gap does persist about organizational implications when it comes to implement collaborative robotics in the workplace and to support proper HRC. Thus, this paper aims to identify recommended human resources management (HRM) practices from previous research about human-robot interaction (HRI). As our results highlight that few studies attempted to fill the gap, a conceptual framework is proposed. It integrates HRM practices, technology adoption dimensions and main determinants of $H R C$, in the objective to support collaborative robotics implementation in organizations.
\end{abstract}

\section{Introduction}

Information Systems (IS) research on technology adoption related to organizational and individual behavior [1] has been highly developed in the recent decade. It concurs with Industry 4.0 (I4.0), where digitalization within organizations is growing at an important rate with smarter [2], more autonomous, and even self-conscious systems [3]. In Canada, 900,000 jobs in the manufacturing industry could be automated or robotized in the future, which represents $61 \%$ of the entire Canadian manufacturing industry [4]. While this technological shift offers great opportunities for organizations, research highlights how challenging technological implementation and adoption can be, especially when it involves workers closely [1].

Indeed, technological implementations can become stressful, affecting workers' health, satisfaction and commitment [5]. Knowing that dissatisfaction among employees can lead to turnover intentions [6], this may become problematic in the current context where organizations are facing human resources shortages [7]. Consequently, neglecting human factors when implementing new and emerging technologies can be risky [8]. Furthermore, the shift triggered by I4.0 changes the external environment where organizations will face more competitiveness [9]. In this highly dynamic context, organizations have a low margin of error when leading their human resources through digitalization. However, efforts to overcome the challenging aspects of a technological implementation may be worth it as it can lead to greater organizational performance [1]. It is notably the case of collaborative robotics that can enable organizations to increase their productivity and efficiency, and to reduce their costs $[10,11]$.

What characterizes collaborative robotics is that it occurs between a robot and a user in a common workspace specifically designed for human-robot collaborative tasks $[12,13]$. Thus, collaborative robotics is built upon the idea of a close interaction between humans and robots. As this topic is less explored from an organizational perspective, more research in IS addressing this aspect is needed.

Then, the main contribution of this paper is to help fill this gap through three objectives. First, this paper investigates the gap concerning the integration of HRM and collaborative robotics adoption through a systematic literature review (SLR). The purpose of this approach is to situate the level of knowledge in research regarding HRM practices involved in organizational HRC. Second, following the SLR, the paper explores the factors responsible for enhancing or hindering $\mathrm{HRC}$ and suggests a preliminary 
conceptualization of the role of HRM practices towards optimal HRC through technology adoption theories. The suggested framework identifies factors that organizations need to take into account when implementing collaborative robotics, especially if they want to reach the full potential it can offer. Oriented towards change management, technological adoption and HRM, it emphasizes the need for interdisciplinary work in the future.

\section{Theoretical background}

\subsection{Human-robot collaboration}

Robots must be differentiated from conventional automated systems because they vary in their behavioral characteristics, namely in autonomy and mobility [14], and in their physical characteristics, such as anthropomorphism or zoomorphism [15]. Robots designed for HRC also require to be differentiated from other teleoperated robots [16] as HRC emphasizes teamwork and autonomy from the robot counterpart [17]. In this line, Yanco and Drury [18] propose a complete taxonomy for human-robot interaction (HRI), considering it a subfield of humancomputer interaction (HCI). Their taxonomy classifies HRI according to the robot's level of autonomy vs the human intervention needed, the human-robot ratio, decision support interfaces, task criticality, time-space and types of robot. Ultimately, these categories frame a continuum on which HRI varies. HRC can be considered as a form of HRI, but more oriented towards collaboration and teamwork.

Thus, HRC have modalities of its own to take into account in the manufacturing industry. Besides, collaborative robots are different from other types of industrial robots as they will not serve the same purposes. Until now, industrial robots have been more isolated from humans for safety measures, whereas collaborative robots share the workspace with them $[13,19]$. Then, various tasks can be divided between humans and robots benefiting from each other's strengths. Robot would take care of tasks that need a fair amount of physical power and that are repetitive, while workers can focus on tasks requiring human capabilities [12].

To understand HRI, Murphy et Schreckenghost [20] suggested three categories of metrics: humans, robots and the system. In their attempt at a preliminary classification, human-related metrics referred to elements like trust, workload or accuracy of mental models. Robot-related metrics included elements like time spent in autonomous or controlled mode or selfawareness. System-related metrics are numerous and include elements such as safety, effectiveness, efficiency and team productivity. To our knowledge, there is not much variety in the classifications of factors that can influence the multiplicity of HRI metrics, however, trust is a popular topic in HRI as it is believed that it is a main determinant of a successful collaboration [21].

\subsection{Technological change in organizations}

There is no doubt that integrating technology in the workplace has the potential to positively affect organizational performance. However, such technological integration have major consequences on the workforce, as it will not only witness alterations in existing jobs but also the inevitable loss of a number of them [22]. Thus, it becomes legitimate that some workers feel anxiety and reluctance to change [23, 24]. In addition, the radical nature of the change and the complexity of the implemented technology may influence employees' skills development and satisfaction, which will affect the success of the change [25]. A growing presence of technological change in work environment can also have adverse effects on workers' health [26]. Besides health consequences related to technologically-induced stress (or technostress), there are also organizational consequences to consider, as technostress hinders satisfaction and commitment at work [5].

Moreover, changes inside the workforce may pose a significant challenge to technological implementations in organizations. Companies may face challenging labor shortages, coupled with new needs in terms of recruitment, training and retention [27]. Additionally, the capabilities needed in the workforce vary on an individual, cultural, gender or generational basis [28]. For example, older workers may be more reluctant to use new technologies [29] or may present different needs in training and skills development [30].

\subsection{Reaching optimal HRC through an HRM perspective}

It is essential to ensure that an optimal synergy occurs between workers and robots. Yet, beyond the factors related to individuals and technologies, factors related to management and work environment can contribute significantly to technology adoption [31]. When it comes to collaborative robotics implementation, specific literature pulled from information and communication technology (ICT) or advanced manufacturing technology (AMT) fields gives great leads for HRM. For instance, organizations 
may have to work on performance assessment, promoting leadership, empowering the workforce [32] and creating incentives [33] in order to ensure the success of the organizational change. Ultimately, workers should be prepared and developed throughout the whole implementation process, even during the pre-implementation, and be aware of the possible consequences related to the robot $[32,34]$.

In addition to training, incentives or rewards [35], support from management is crucial when it comes to innovation adoption [33] and AMT implementation. This calls for practices that are included in seven major HRM activities (job analysis, HR planning, recruitment, selection, performance assessment, compensation and training) [36]. While robotics differs from ICTs or other AMT, research emphasizes the need to adapt HRM practices to the type of technology implemented [37]. There is not, however, enough documentation about the role of these practices for collaborative robotics implementation.

\section{Method}

This paper presents a SLR following guidelines suggested by Tranfield, Denyer \& Smart [38]. This research method includes three main phases: (1) review planning, (2) review performance and (3) data extraction and synthesis.

Review planning: A set of 48 searched keywords, presented in Table 1, was developed. These words were related to the human-machine/robot interaction, HRM practices and human factors. The goal was to find papers that connected HRC and HRM. We used these keywords to search in five databases (ABI/INFORM, Scopus, PsycInfo, Computer and Applied Science Complete, Business Source Complete and Emerald). These databases cover relevant literature in various fields of this research.

Given the lack of research linking HRM practices and HRC, the extracted data was not comprehensive enough to write a thorough literature review on this topic, even when considering human-computer or more general man-machine interaction literature. We then used the same pool of articles but broadened the scope to include a background of HRI metrics. Therefore, our inclusion criteria were papers: (1) presenting conceptual or empirical findings related to human metrics, human factors or HRM practice to robot use, (2) presenting findings based on human participants when the papers were empirical, (3) being published in English, between January $1^{\text {st }} 2010$ and May $18^{\text {th }} 2018$, and (4) being published as a peerreviewed journal paper or conference paper. We excluded papers according to the following criteria: (1) if the robots were teleoperated or if the robot system had no autonomy, (2) if the robot was an automated vehicle, (3) if the study did not include humans, (4) if the study did not present conceptual or empirical findings, (5) if it was a conference paper presenting the same results as a selected journal paper, and (6) if it studied automation or other machines instead of robots. Also, since we broadened the scope of our SLR, we only considered papers about HRC and HRI to keep some specificity.

Table 1. Searched keywords

$$
\text { Collaborative robotics }
$$

Intelligent machine*, Collaborative robotic*, Man-machine collaboration, Man-Machine interact*, Man-Machine relation*, Man machine collaboration, Man Machine interact*, Man Machine relation*, Human-robot collaboration", Human-robot interact*, Human-robot relation*, Human robot collaboration, human robot interact*, Human robot relation*, HRC, HRI, Human-agent teaming, Human agent teaming, Human-computer collaboration, Human-computer interaction, Human-computer relation*, Human computer collaboration, Human computer interact*, Human computer relation*, HCC, HCI.

\section{AND}

Human resources management and human factors

Human resource management, Human resources management, HRM, Human resources management pract*, HRM pract*, Human resources management act*, HRM act*, organi* train*, organi* communic*, employ* participation, operator participation, trust, leadership, human factor, human-factor, manag* support, organi* support, supervi* support, HR commitment, change management, employ* commitment, human resource* commitment.

Review performance: The database search led to a total of 591 papers. After eliminating duplicates, and reading titles and abstracts, a set of 139 papers was selected according to our inclusion/exclusion criteria. Then, we used a qualitative analysis software (Nvivo) to code the papers according to their methodology and relevant findings. We eliminated more publications that did not meet our criteria. During this step, the peer-review aspect was validated when necessary. Ultimately, we selected a total of 67 papers for further data extraction and analysis (a full list is available on demand). 
Data extraction: The data analysis software helped to code and classify information contained in the paper. The results, discussions and conclusions of each paper were analyzed, as they could provide new empirical information or insight from the authors. The categories related to humans, robots, the environment, HRM practices and even research agendas were defined.

\section{Results}

\subsection{Descriptive analysis}

We selected 67 papers, which includes 51 conference publications $(76.1 \%)$ and 16 journal publications. Most of the papers were from the ACM/IEEE International Conference on HumanRobot Interaction, and the Human Factors and Ergonomics Society with 11 publications (16.4\%) each. The numbers then drop between 5 to 1 for other conferences and journals.

Figure 1 shows trends in publication according to the year of publication. First, it highlights a growing interest from researchers around 2016 and 2017 that presents the highest publication level. The lowest number of publications between 2010 and 2011 may be due to the novelty of the topic at this time. The number of publications also decrease in 2018, compared to 2017, most likely because of the date the search was conducted. Thus, papers published after May $18^{\text {th }}$ are not included in the results for the year 2018.

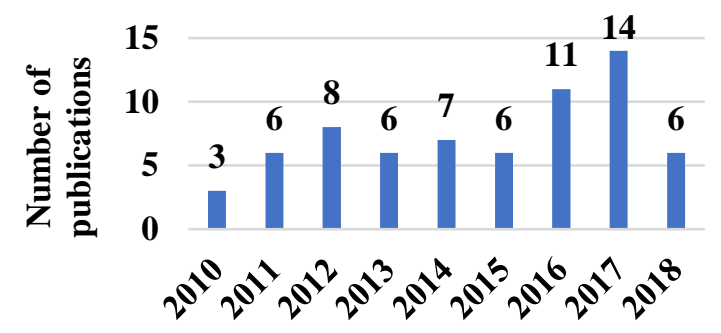

Figure 1. Classification by publication dates

Regarding research methodology approaches, Figure 2 shows a classification by main categories. Conceptual work mostly refers to literature review or theoretical analysis and ideas about HRI/HRC, with no empirical work, whereas empirical work is based on measurable data [39]. Results suggest a large proportion of experimental and quantitative research work, which represents $44(64 \%)$ of all the selected papers. There are also fewer publications using a qualitative approach and conceptualizing the topics of HRI and HRC. More specifically, there is also a lack of case studies. Overall, these results indicate that literature may show a lack of diversity in methodological approaches.

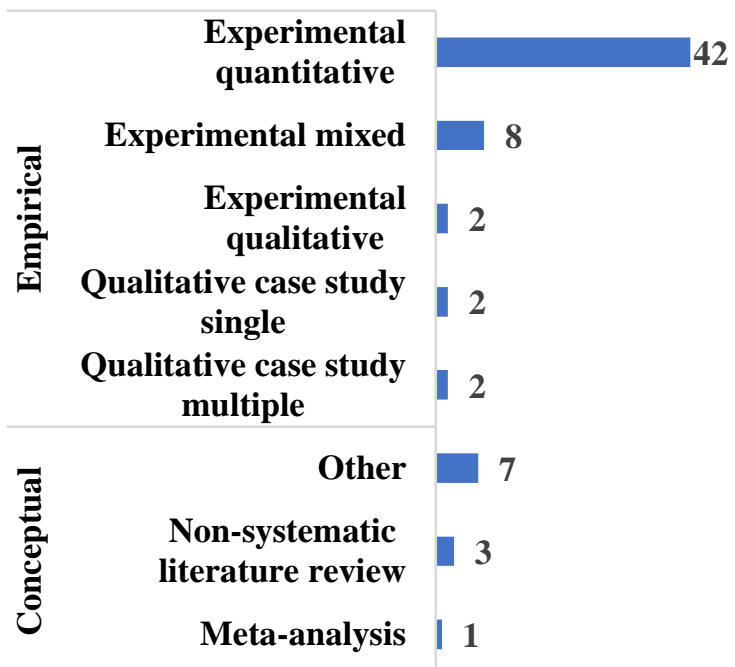

Figure 2. Classification by research method

\subsection{Qualitative analysis of literature}

4.2.1. Attempt to identify HRM implications. Few papers investigated HRC from an HRM perspective. Indeed more papers addressed robot design and programming [40-43]. Still, some HRM-related challenges and practices have been identified, such as training, change management, workforce's fear of job loss and unionized work environment. These challenges can hinder collaborative robotics implementation in manufacturing organizations and will call for greater focus on human resources management [19]. It is also essential to promote active employee participation in the integration process. Indeed, continually informing employees would help reduce resistance to change [44]. This includes communication with unions and their inclusion into the process [45].

Besides the implementation itself, organizations must keep ensuring a safe work environment for their employees. This will require greater attention to safety features when choosing the robots and the integration of health and safety management practices [13, 46]. Ultimately, the work that addressed managerial implication the most specifically comes from Charalambous and his collaborators [8, 45]. They emphasize the importance of employee inclusion and empowerment, top-down communication and active involvement from senior management. They also suggest identifying a project manager, whom they call a process champion, which acts as an important middleman in the process coordination and communication to the parties involved. 
The work synthesized above represents the principal contributors retrieved from the selected papers. Interestingly, only one paper ([19]) was published in an HRM-related journal (SA Journal of Human Resource Management). This suggests that even when addressing management practices in a collaborative robotics context, research may not be published in the journals usually consulted by HRM professionals. The other papers were published in The International Journal of Advanced Manufacturing Technology, Human Factors and Ergonomics Society Annual Meeting, Human Factors and Ergonomics in Manufacturing \& Service Industries or International Journal of Advanced Robotic Systems. Three of them were qualitative case studies and two were empirical quantitative researches.

4.2.2. Factors influencing HRC. As observed above, very few papers have investigated the topic of HRC from an HRM perspective. For this reason, we broadened the scope of the SLR. We included the factors that will impact HRI, as these factors are susceptible of being involved in HRC too. We believe that these factors may influence HRM deployment in the implementation process.

Key background elements were split into three categories: human-related factors, robot-related factors and environment-related factors. This categorization was established following the analysis of the data retrieved during the reading phase. The major assessment regarding the categories is shown in Table 2, which summarizes the first and second-level categories and the principal contributors. Almost all the analyzed papers are mentioned in this table. It illustrates that robot-related factors are studied the most, especially robot's performance, which included elements like the robot's motion, speed and external features, such as physical appearance. Regarding human-related factors, users' previous experiences appear addressed the most. Environment-related factors are the least covered of the three.

Table 2. Factors identified in the selected papers

\begin{tabular}{|c|l|}
\hline Human-related factors & \multicolumn{1}{c|}{ References } \\
\hline Demographics & {$[\mathrm{P} 19, \mathrm{P} 25, \mathrm{P} 38, \mathrm{P} 63]$} \\
\hline Individual characteristics & {$[\mathrm{P} 7, \mathrm{P} 14, \mathrm{P} 19, \mathrm{P} 22, \mathrm{P} 45]$} \\
\hline Perception of health and safety & {$[\mathrm{P} 6, \mathrm{P} 23, \mathrm{P} 32, \mathrm{P} 54, \mathrm{P} 67]$} \\
\hline Previous experiences & {$[\mathrm{P} 1, \mathrm{P} 5, \mathrm{P} 6,16, \mathrm{P} 18, \mathrm{P} 27, \mathrm{P} 31, \mathrm{P} 33, \mathrm{P} 39, \mathrm{P} 43, \mathrm{P} 47, \mathrm{P} 53, \mathrm{P} 54, \mathrm{P} 60, \mathrm{P} 62]$} \\
\hline Robot-related factors & \multicolumn{1}{|c|}{ Refences } \\
\hline Information sharing & {$[\mathrm{P} 8, \mathrm{P} 17, \mathrm{P} 26, \mathrm{P} 29, \mathrm{P} 40, \mathrm{P} 48, \mathrm{P} 50, \mathrm{P} 57, \mathrm{P} 61, \mathrm{P} 64]$} \\
\hline Performance & {$[\mathrm{P} 6, \mathrm{P} 8, \mathrm{P} 11, \mathrm{P} 12, \mathrm{P} 13, \mathrm{P} 16, \mathrm{P} 18, \mathrm{P} 23, \mathrm{P} 29, \mathrm{P} 30, \mathrm{P} 34, \mathrm{P} 36, \mathrm{P} 42, \mathrm{P} 44, \mathrm{P} 58, \mathrm{P} 59]$} \\
\hline External features & {$[\mathrm{P} 2, \mathrm{P} 6, \mathrm{P} 25, \mathrm{P} 27, \mathrm{P} 31, \mathrm{P} 35, \mathrm{P} 37, \mathrm{P} 38, \mathrm{P} 39, \mathrm{P} 41, \mathrm{P} 44, \mathrm{P} 45, \mathrm{P} 48, \mathrm{P} 49, \mathrm{P} 52, \mathrm{P} 56$,} \\
\hline Social and cognitive behaviors & {$[\mathrm{P} 10, \mathrm{P} 15, \mathrm{P} 17, \mathrm{P} 20, \mathrm{P} 21, \mathrm{P} 24, \mathrm{P} 28, \mathrm{P} 31, \mathrm{P} 46, \mathrm{P} 49, \mathrm{P} 51, \mathrm{P} 55, \mathrm{P} 65]$} \\
\hline Environment-related factors & \\
\hline Tasking & {$[\mathrm{P} 4, \mathrm{P} 9, \mathrm{P} 38]$} \\
\hline Context & {$[\mathrm{P} 15, \mathrm{P} 21, \mathrm{P} 38]$} \\
\hline
\end{tabular}

\section{Discussion}

Our results show that there is a lack of integration of HRM practices and HRC in research. The lack of qualitative case studies on the matter may contribute to the scarcity observed in the literature. In addition, as robot-related factors are more addressed in the literature, this may explain why there are more research-based recommendations concerning the design and programming of robots. Additionally, because of past struggles to include $\mathrm{HR}$ as a major player in organizations [47], lesser importance may be given to HR role in organizational strategies.

In the following sections, we attempt a preliminary conceptualization of how HRM practices and organizational collaborative robotics adoption can be integrated using the Technology Acceptance Model (TAM) [48]. As we could not establish a sufficiently broad portrait of HRM implications and practices, we used the SLR to inventory determining factors of HRC. The hypothesis being that these factors would help us link HRM to HRC and collaborative robotics adoption.

\subsection{Collaborative robotics adoption}

We chose the the TAM [48] as it is already well documented in the literature. In this model, usage of the technology is indirectly influenced by two main variables: "perceived ease of use (PEU)" and "perceived usefulness (PU)". Their relationships are 
mediated by the attitude towards use and behavioral intention to use.

Also, PEU and PU can be influenced by external variables [49]. These variables can be quite numerous, but a synthesis of the literature by Venkatesh and Bala [50] identifies four main categories of decisive factors: "individual differences", "system characteristics", "social influence" and "facilitating conditions". Figure 3 shows the model issued from Davis et al. [48], combined to Venkatesh's and Bala's [50] addition.

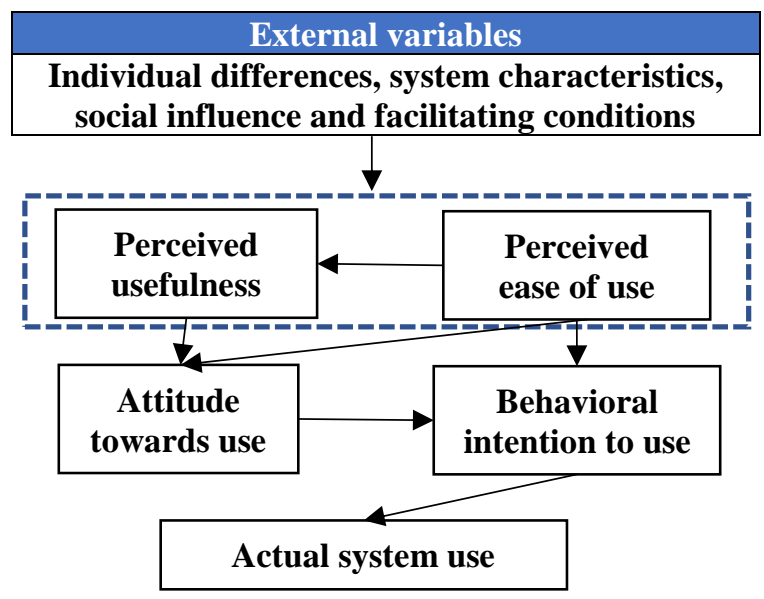

Figure 3. TAM's theoretical framework based on Davis et al. [48] and, Venkatesh and Bala [50]

Extrapolating the TAM to collaborative robotics and the factors from Table 2, human, robot and environment-related factors could be determinants of PEU and PU. As for the HRM implications identified in Section 4.2.1., they would probably be considered as a facilitating condition, this variable mainly referring to support from the organization [50]. In fact, possible relationships between the roles of an HR department and variables of the TAM have been suggested before [51, 52].

Globally, four specific HR roles taken from Ulrich's work [53] (administrative expert, employee champion, change agent and strategic partners) may have an influence on PU and PEU [51]. For example, the employee champion can listen to the needs of employees in a context of change, the strategic partner can align HR practices with business strategy and business objectives, the change agent can facilitate employees' commitment to change through deployment of transformation-consistent practices and the administrative expert can monitor HR indicators to track productivity [53]. Thus, beyond using the TAM to understand collaborative robotics adoption, we might benefit from including a more complete change management perspective in the model. Figure 4 presents how the variables from our SLR could be related to the TAM. The extended model is a start in suggesting how practices in Section 4.2.1. and factors from Table 2 are susceptible of influencing the employees' acceptance of collaborative robots.

The conceptualization based on HR role is that it does not solely include the operational role of HRM. It also positions the HR department as a strategic and active player in the ongoing change and technology adoption. Yet, from a broader change management perspective, HRM implications may be underestimated in the model.

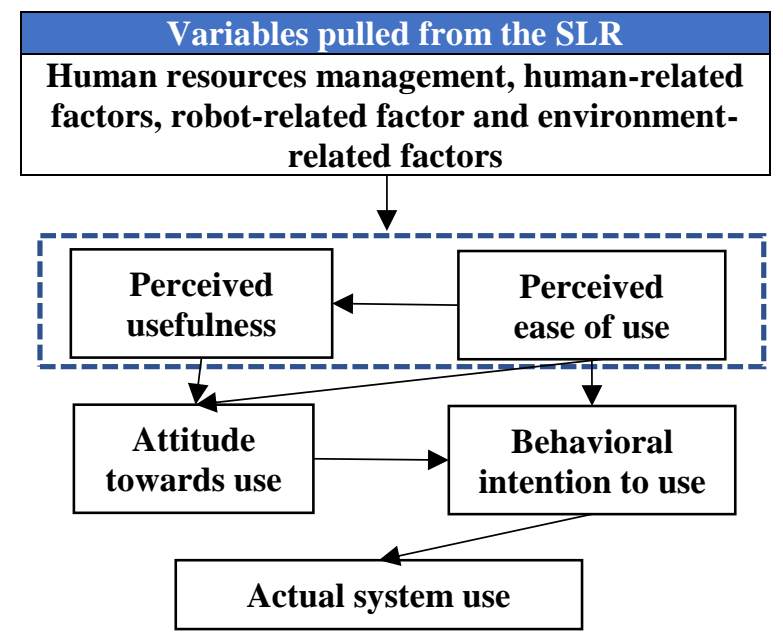

Figure 4. Possible relationships between findings in the SLR and the TAM

\subsection{Integrating HRM to the TAM from a change management perspective}

Findings presented in Section 4.2. find echo within the change management process. Indeed, Maheshwari and Vohra [54] suggested that HRM practices in regards to culture, leadership, cross functional integration, training, communication and technology may have a significant impact on employees' acceptance and commitment to the change. They also suggest that employees need to have a positive perception of managers' intentions through the HRM practices, which may mediate the relationship between these practices and commitment to change. While their framework remains at a theoretical state, it adopts the same perspective as Neves and colleagues [55], who mentioned that HR practices can affect intention to resist change through affective commitment to change and a moderating effect of ethical leadership from the direct supervisor. These works could also support the fact that alignment of HRM practices with work 
transformation is essential in a strategic HRM perspective [36, 56] and technology adoption [57].

This leads us to emphasize the need for HRM practices to be strongly integrated throughout the whole technological change process. This means that HRM practices should involve HR professionals, but also any manager and supervisor navigating the change. Furthermore, organizations may not be required to go above and beyond in terms of HRM practices implementation. Indeed, results suggest that some practices may be more important to employees than others, such as communication or rewards [58]. Hence, less may be more in times of change.

In the end, putting greater focus on commitment to change is likely to be a decisive factor as it is "a force (mindset) that binds an individual to a course of action deemed necessary for the successful implementation of a change initiative" (p. 475) [59]. Hence, commitment to change can lead to higher behavioral support from employees towards the change [59], which could translate into using the implemented technology. Therefore, the integration of commitment to change to the TAM would suggest that HRM practices may have a greater influence on technology adoption than anticipated. Figure 5 illustrates our attempt to conceptualize collaborative robotics adoption and HRC with an emphasis on the possible outcomes of HRM practices, which is lacking in the literature.

The variables proposed to extend the TAM are the commitment to change and HRC-related factors that go beyond simple usage of the system. Based on the previous sections, we highlight possible relationships between HRM practices, commitment to change and the TAM. The suggested relationships are illustrated with bold black and blue arrows.

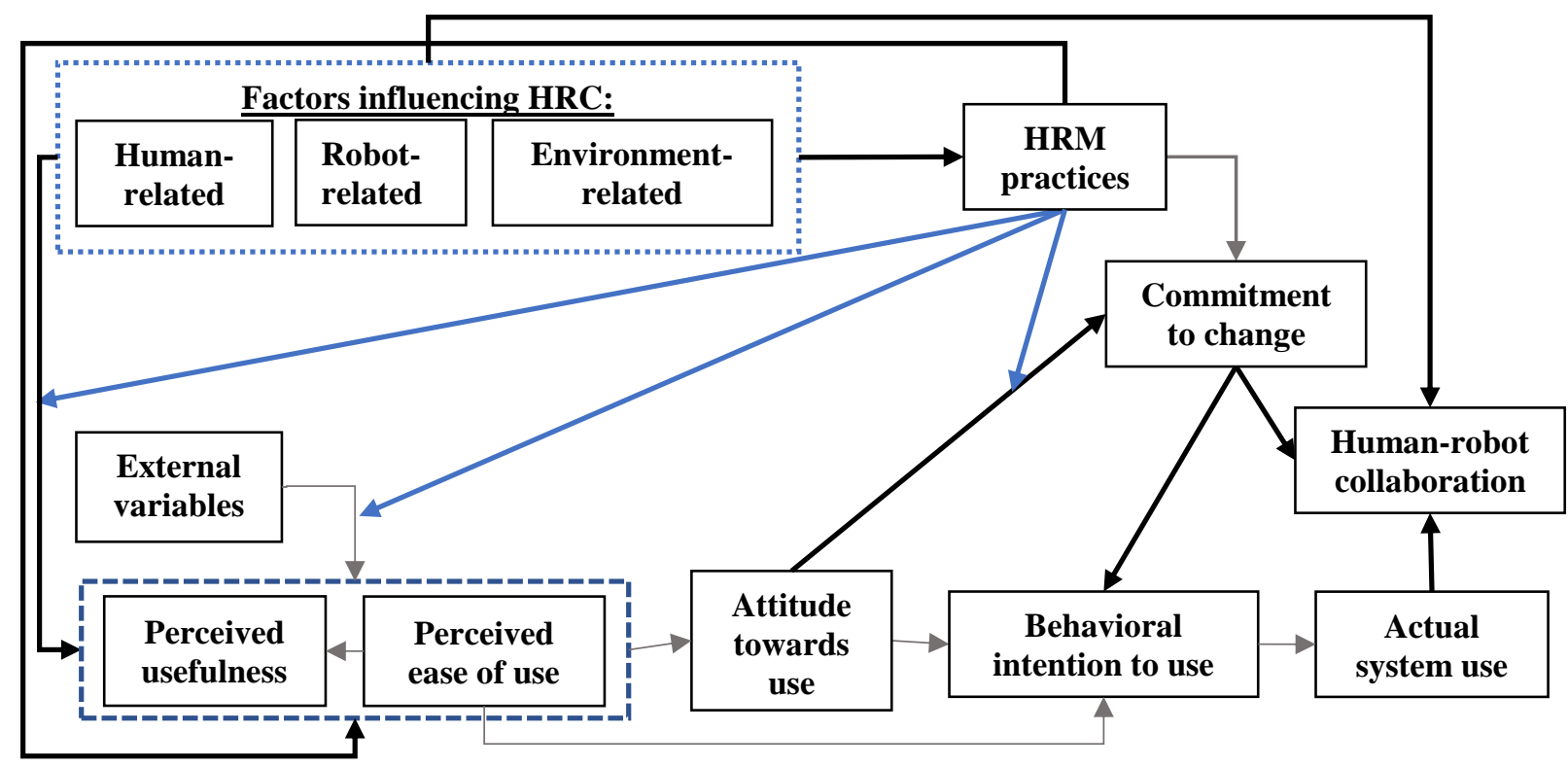

Figure 5. Integrated framework of TAM and HRM practices for collaborative robotics

HRM practices may also moderate the influence of factors related to HRC and other external variables on PEU and PU. For example, enabling employees' capabilities to work efficiently within a collaborative cell through specific training could augment PEU. We also believe that HRM practices could directly influence initial variables of the TAM. Indeed, appropriate communication could inform employees of the changes going on, likely affecting PU directly or moderating the effect of attitude towards use. Moreover, specific HRM practices may promote attitudes that are more positive or affect behavioral intention, technology usage and HRC by enhancing commitment to change. In that case, one of many possibilities is that HRM practices oriented towards empowerment or the creation of incentives could promote HRC through employees' commitment to change and actual use of the system.

Additionally, special care from management regarding workers' psychological safety may be advised as it can be affected by stressors like induced work overload or job precariousness [60]. This is where managers and HR professionals may work on redefining job content and training in order to prevent those. HRM practices may even mediate the effect that the fear of job loss could have on commitment to change or technology usage. But doing so, human factors such as demographic variables, individual characteristics or previous experiences cannot be overlooked as some may have a mediating, or moderating, effect on HRM practices. It is also possible that those factors will directly affect initial 
attitudes towards use. In the end, the relevance of a better integration of HRM practices becomes even more important when facing potentially negative consequences of collaborative robotics on the workforce.

\section{Conclusion and limitations}

By means of an SLR, we attempted to pinpoint HRM practices and implications relative to collaborative robotics adoption and HRC. The relationship between HRC and HRM remains tenuous in research. To fill the gap, we believe that a thorough investigation of the relationship between the factors related to HRC and HRM practices is necessary. Thus, our proposition is to integrate HRM practices to technology adoption models in an organizational context, along with the three fundamental categories of factors (human, robot and environment) impacting HRC. We also believe that our work may be used for other technological implementations. Indeed, beyond the type of technology implemented, HRM must be strategic and proactive. In terms of knowledge, this may also require more cooperation between research disciplines [61], as the determinants of HRC appears transdisciplinary.

The main limitation of this SLR is that it cannot ensure complete inclusivity due to our inclusion criteria and the keywords used in the databases. Besides, we had to broaden our inclusion criteria because we did not find enough studies on HRM practices regarding industrial collaborative robotics implementation. Moreover, given the multidisciplinary nature of the phenomenon, keywords are likely to vary from one discipline to another. Consequently, some relevant studies may not have shown through our research in the databases due to our own keyword selection. Ultimately, feasibility has restrained the result overview. Due to the lack of space, details on determinants of HRC specific outcomes and the various nuances presented in the literature are not presented in this paper.

\section{Research agenda}

We need to emphasize the need to adapt HRM practices to the variations from the type of technology implemented [37], and the stage of the implementation [62]. This could lead to a detailed roadmap of required HRM practices and possible retroaction loops. In fact, part of our ongoing work in determining factors of HRC echoes with You and Robert's work about human-robot teamwork [63]. However, adding an HRM perspective could be useful for practitioners. In this line, performing more case studies may prove interesting as it can provide more insight on HRC and HRM practices based on context [64]

We also believe that this paper opens a door to many interesting research avenues, as the model in Figure 5 should be subject to further research in IS. Indeed, many relationships and their complexity are not illustrated. Therefore, interaction of the determinants of HRC and the variables in the TAM, along with our current propositions should be explored further. For instance, users' previous experience could be positioned as moderators instead of determinants [62]. Performing a SLR specific to the subject may give interesting insights for further developments. Also, trust was indicated as a major determinant of optimal HRC. However, the relationship between trust, HRC and known technological adoption models seems overlooked in the literature.

Ultimately, with the objective to better understand, to confirm or to refute possible relationships illustrated in Figure 5, we suggest the following questions: How should HRM practices be involved through the various phases of collaborative robotics implementation? What variables will be more influenced by HRM practices, whether it is through a direct effect or moderating/mediating effects? How will the main factors determining HRC (human, robot and environment) impact the effect of HRM practices on adoption and commitment to change? How will HR departments, management and supervisors need to collaborate in collaborative robotics implementation?

\section{References}

[1] T. Oliveira and M. F. Martins, "Literature review of information technology adoption models at firm level", Electronic Journal of Information Systems Evaluation, Vol. 14, no. 1, 2011, p. 110-121.

[2] T. K. Sung, "Industry 4.0: A Korea perspective", Technological Forecasting and Social Change, Vol. 132, pp. 40-45, 2018.

[3] N. Tuptuk and S. Hailes, "Security of smart manufacturing systems", Journal of Manufacturing Systems, Vol. 47, 2018, pp. 93-106.

[4] M. Chui, J. Manyika, and M. Miremadi, "Four fundamentals of workplace automation", McKinsey Quarterly, Vol. 29, no. 3, 2015, pp. 1-9.

[5] L. Atanasoff and M. A. Venable, "Technostress: Implications for Adults in the Workforce", The Career Development Quarterly, Vol. 65, no. 4, 2017, pp. 326-338.

[6] L. Li, Y. Zhu, and C. Park, "Leader-Member Exchange, Sales Performance, Job Satisfaction, and Organizational Commitment Affect Turnover Intention", Social Behavior and Personality: An International Journal, Vol. 46, no. 11, 2018, pp. 1909-1922.

[7] Statistics Canada. 2019. "Postes vacants, employés salariés, taux de postes vacants et moyenne du salaire horaire offert selon le secteur de l'industrie, données trimestrielles non 
désaisonnalisées", Retrieved February 24th, 2019, from https://www150.statcan.gc.ca/t1/tbl1/fr/tv.action?pid=141003 2601

[8] G. Charalambous, S. Fletcher, and P. Webb, "Identifying the key organisational human factors for introducing humanrobot collaboration in industry: an exploratory study", The International Journal of Advanced Manufacturing Technology, Vol. 81, no. 9-12, 2015, pp. 2143-2155.

[9] M. A. Shehadeh, S. Schroeder, A. Richert, and S. Jeschke, "Hybrid teams of industry 4.0: A work place considering robots as key players", In 2017 IEEE International Conference on Systems, Man, and Cybernetics (SMC), IEEE, Banff, AB, 2017, pp. 1208-1213.

[10] R. Bloss, "Collaborative robots are rapidly providing major improvements in productivity, safety, programing ease, portability and cost while addressing many new applications", Industrial Robot: An International Journal, Vol. 43, no. 5, 2016, pp. 463-468.

[11] D. Richards, "Escape from the factory of the robot monsters: agents of change", Team Performance Management: An International Journal, Vol. 23, no. 1/2, 2017, pp. 96-108.

[12] International Organization for Standardization. 2016. "Robots and Robotic Devices - Collaborative Robots", Retrieved February 24 ${ }^{\text {th }}, 2019$, from https://www.iso.org/ob p/ui/\#iso:std:iso:ts:15066:ed-1:v1:en

[13] M. Koppenborg, P. Nickel, B. Naber, A. Lungfiel, and M. Huelke, "Effects of movement speed and predictability in human-robot collaboration", Human Factors and Ergonomics in Manufacturing \& Service Industries, Vol. 27, no. 4, 2017, pp. 197-209.

[14] D. Ishak and D. Nathan-Roberts, "Analysis of Elderly Human-Robot Team Trust Models", Proceedings of the Human Factors and Ergonomics Society Annual Meeting, Vol. 59, no. 1, 2015, pp. 65-69.

[15] M. Desai, K. Stubbs, A. Steinfeld, and H. Yanco, "Creating Trustworthy Robots: Lessons and Inspirations from Automated Systems", In Proceedings of Artificial Intelligence and Simulation of Behaviour Convention: New Frontiers in Human-Robot Interaction, Edinburgh, Scotland, 2009, pp. 18.

[17] G. Hoffman and C. Breazeal, "Collaboration in HumanRobot Teams", In AIAA 1st Intelligent Systems Technical Conference, AIAA, Chicago, IL, 2004, pp. 1-18

[18] H. A. Yanco and J. L. Drury, "A taxonomy for humanrobot interaction," In Proceedings of the AAAI Fall Symposium on Human-Robot Interaction, North Falmouth, MA, 2002, pp. 111-119.

[19] A. P. Calitz, P. Poisat, and M. Cullen, "The future African workplace: The use of collaborative robots in manufacturing", South African Journal of Human Resource Management, Vol. 15, no. 1, 2017, pp. 1-11.

[20] R. R. Murphy and D. Schreckenghost, "Survey of metrics for human-robot interaction", In 2013 8th ACM/IEEE International Conference on Human-Robot Interaction (HRI), Tokyo, Japan, 2013, pp. 197-198.

[21] D. R. Billings, K. E. Schaefer, J. Y. C. Chen, and P. A. Hancock, "Human-robot interaction: developing trust in robots", In Proceedings of the seventh annual ACM/IEEE international conference on Human-Robot Interaction, ACM, Boston, MA, 2012, p. 109-110.
[22] E. Noël, Automatisation, nouveaux modèles d'affaires et emploi: une prospective québécoise, Institut du Québec, Montréal, QC, 2017.

[23] P. Schneider, "Managerial challenges of Industry 4.0: an empirically backed research agenda for a nascent field", Review of Managerial Science, Vol. 12, no. 3, 2018, pp. 803848.

[24] S. Luthra and S. K. Mangla, "Evaluating challenges to Industry 4.0 initiatives for supply chain sustainability in emerging economies", Process Safety and Environmental Protection, Vol. 117, 2018, pp. 168-179.

[25] L. Aiman-Smith and S. G. Green, "Implementing new manufacturing technology: The related effects of technology characteristics and user learning activities", Academy of Management Journal, Vol. 45, no. 2, 2002, pp. 421-430.

[26] B. Brinzer and A. Banerjee, "Measuring the Human Aspect: The Key for Managing the Complexity in Production", In Advances in Ergonomics of Manufacturing: Managing the Enterprise of the Future, Springer, Vol. 606, 2018, pp. 14-24.

[27] B. Sivathanu and R. Pillai, "Smart HR 4.0 - how industry 4.0 is disrupting HR", Human Resource Management International Digest, Vol. 26, no. 4, 2018, pp. 7-11.

[28] D. Kerpen, M. Lohrer, M. Saggiomo, M. Kemper, J. Lemm, and Y.-S. Gloy, "Effects of cyber-physical production systems on human factors in a weaving mill: Implementation of digital working environments based on augmented reality", In 2016 IEEE International Conference on Industrial Technology (ICIT), IEEE, Vol. 2016, pp. 2094-2098.

[29] A. Khan and K. Turowski, "A perspective on industry 4.0: From challenges to opportunities in production systems", In Proceedings of International Conference on Internet of Things and Big Data, 2016, pp. 441-448.

[30] M. Peruzzini and M. Pellicciari, “A framework to design a human-centred adaptive manufacturing system for aging workers", Advanced Engineering Informatics., Vol. 33, 2017, pp. 330-349.

[31] V. Peansupap and D. Walker, "Exploratory factors influencing information and communication technology diffusion and adoption within Australian construction organizations: a micro analysis", Construction Innovation, Vol. 5, no. 3, 2005, pp. 135-157.

[32] M. H. Small, "Planning, justifying and installing advanced manufacturing technology: a managerial framework", Journal of Manufacturing Technology Management, Vol. 18, no. 5, 2007, pp. 513-537.

[33] M. Talukder, "Factors affecting the adoption of technological innovation by individual employees: An Australian study", Procedia - Social and Behavioral Sciences, Vol. 40, 2012, pp. 52-57.

[34] M. H. Small and M. Yasin, "Human factors in the adoption and performance of advanced manufacturing technology in unionized firms", Industrial Management \& Data Systems, Vol. 100, no. 8, 2000, pp. 389-402.

[35] S. A. Snell and J. W. Dean Jr, "Integrated manufacturing and human resource management: A human capital perspective", Academy of Management Journal, Vol. 35, no. 3, 1992, pp. 467-504.

[36] G. L. Stewart and K. G. Brown, Human Resource Management, 3rd ed, Wiley, Hoboken, NJ, 2014. 
[37] D. S. Siegel, D. A. Waldman, and W. E. Youngdahl, "The adoption of advanced manufacturing technologies: human resource management implications", IEEE Transactions on Engineering Management, Vol. 44, no. 3, 1997, pp. 288-298. [38] D. Tranfield, D. Denyer, and P. Smart, "Towards a Methodology for Developing Evidence-Informed Management Knowledge by Means of Systematic Review", British Journal of Management, Vol. 14, no. 3, 2003, pp. 207 222.

[39] S. S. Kamble, A. Gunasekaran, and S. A. Gawankar, "Sustainable Industry 4.0 framework: A systematic literature review identifying the current trends and future perspectives", Process Safety and Environmental Protection., Vol. 117, 2018, pp. 408-425.

[40] K. E. Schaefer, J. G. Cook, J. K. Adams, J. Bell, T. L. Sanders, and P. A. Hancock, "Augmented Emotion and its Remote Embodiment: The Importance of Design from Fiction to Reality", Proceedings of the Human Factors and Ergonomics Society Annual Meeting, Vol. 56, no. 1, 2012, pp. 1817-1821.

[41] S. You and L. P. Robert Jr., "Human-Robot Similarity and Willingness to Work with a Robotic Co-worker", In Proceedings of the 2018 ACM/IEEE International Conference on Human-Robot Interaction, Chicago, IL, 2018, pp. 251-260. [42] K. Chauncey, C. Harriott, Z. Prasov, and M. Cunha, "A Framework for Co-adaptive Human-Robot Interaction Metrics", In Proceedings of the Workshop on Human-Robot Collaboration: Towards Co-Adaptive Learning Through Semi-Autonomy and Shared Control (HRC). IEEE/RSJ International Conference on Intelligent Robots and Systems, 2016, pp. 1-5.

[43] T. L. Sanders et al., "Trust and Prior Experience in Human-Robot Interaction", Proceedings of the Human Factors and Ergonomics Society Annual Meeting, Vol. 61, no. 1, 2017, pp. 1809-1813.

[44] S. Jocelyn, D. Burlet-Vienney, and L. Giraud, "Experience Feedback on Implementing and Using HumanRobot Collaboration in the Workplace", Proceedings of the Human Factors and Ergonomics Society Annual Meeting, Vol. 61, no. 1, 2017, pp. 1690-1694.

[45] G. Charalambous, S. R. Fletcher, and P. Webb, "The development of a Human Factors Readiness Level tool for implementing industrial human-robot collaboration", The International Journal of Advanced Manufacturing Technology, Vol. 91, no. 5-8, 2017, pp. 2465-2475.

[46] I. Maurtua, A. Ibarguren, J. Kildal, L. Susperregi, and B. Sierra, "Human-robot collaboration in industrial applications: Safety, interaction and trust", International Journal of Advanced Robotic Systems, Vol. 14, no. 4, 2017, pp. 1-10

[47] L. Holbeche, Aligning human resources and business strategy, 2nd ed. Butterworth-Heinemann, Amsterdam, NL, 2009.

[48] F. D. Davis, R. P. Bagozzi, and P. R. Warshaw, "User Acceptance of Computer Technology: A Comparison of Two Theoretical Models", Management Science, Vol. 35, no. 8, 1989, pp. 982-1003.

[49] F. D. Davis, A technology acceptance model for empirically testing new end-user information systems, Cambridge, MA, 1986.
[50] V. Venkatesh and H. Bala, "Technology Acceptance Model 3 and a Research Agenda on Interventions", Decision Sciences, Vol. 39, no. 2, 2008, pp. 273-315.

[51] Y. M. Yusoff, T. Ramayah, and H. Ibrahim, "E-HRM: A proposed model based on technology acceptance model", African Journal of Business Management, Vol. 4, no 14, 2010, pp. 3039-3045

[52] M. Voermans and M. van Veldhoven, "Attitude towards E-HRM: an empirical study at Philips", Personnel Review, Vol. 36, no. 6, 2007, pp. 887-902.

[53] D. Ulrich, Human Resource Champions: The Next Agenda for Adding Value and Delivering Results. Harvard Business Press, Brighton, MA, 1996.

[54] S. Maheshwari and V. Vohra, "Identifying critical HR practices impacting employee perception and commitment during organizational change", Journal of Organizational Change Management, Vol. 28, no. 5, 2015, pp. 872-894.

[55] P. Neves, P. Almeida, and M. J. Velez, "Reducing intentions to resist future change: Combined effects of commitment-based HR practices and ethical leadership", Human Resource Management, Vol. 57, no. 1, 2018, pp. 249261.

[56] P. M. Wright and S. A. Snell, "Toward a unifying framework for exploring fit and flexibility in strategic human resource management", Academy of management review, Vol. 23, no. 4, 1998, pp. 756-772.

[57] W. R. Carroll and T. H. Wagar, "Is there a relationship between information technology adoption and human resource management?", Journal of Small Business and Enterprise Development, Vol. 17, no. 2, 2010, pp. 218-229.

[58] E. Conway and K. Monks, "HR practices and commitment to change: an employee-level analysis: HR practices and commitment to change", Human Resource Management Journal, Vol. 18, no. 1, 2007, pp. 72-89.

[59] L. Herscovitch and J. P. Meyer, "Commitment to organizational change: Extension of a three-component model", Journal of Applied Psychology, Vol. 87, no. 3, 2002, pp. 474-487.

[60] R. Ayyagari, V. Grover, and R. Purvis, "Technostress: technological antecedents and implications", MIS Quarterly, Vol. 35, no. 4, 2011, pp. 831-858.

[61] T. Ellwart et al., "Intentional Forgetting in Socio-Digital Work Systems: System Characteristics and User-related Psychological Consequences on Emotion, Cognition, and Behavior", Systems. AIS Transactions on Enterprise Systems, Vol. 4, no. 1, 2019, p. 1-19.

[62] V. Venkatesh and F. D. Davis, "A Theoretical Extension of the Technology Acceptance Model: Four Longitudinal Field Studies", Management Science, Vol. 46, no. 2, 2000, pp. 186-204.

[63] S. You and L. Robert, "Teaming up with robots: An IMOI (inputs-mediators-outputs-inputs) framework of human-robot teamwork", International Journal of Robotic Engineering, vol. 2, no 3, 2017, pp. 1-7.

[64] P. Baxter and S. Jack, "Qualitative case study methodology: Study design and implementation for novice researchers", The Qualitative Report, Vol. 13, no. 4, 2008, pp. $544-559$. 